\title{
Социамьная педагогика
}

\author{
УДК 37.01, 37.013.78
}

\section{Проектная деятельность как технология и ресурс социализации молодежи}

\section{Project activity as a technology of socialization of youth}

\author{
Турлаков Д.Г., Московский политехнический университет, dmi-turlakov@yandex.ru \\ Турлакова О.Е., Институт стратегии развития образования PAO, olenka1592@ mail.ru
}

Turlakov D., Moscow Polytechnic University, dmi-turlakov@yandex.ru

Turlakova O., Institute for Strategy of Education Development of the Russian Academy of Education,olenka1592@mail.ru

DOI: $10.51379 /$ KPJ.2021.148.4.025

Ключевье слова: социально-проектная деятельность, технологии сочиализации, молодежь, социальное проектирование, социально-ориентированный проект.

Keywords: social project activity, socialization, youth, social design, socially-oriented project.

Аннотация. Системный подход к устойчивому развитию социально-экономической инфраструктурьл России является основой его конкурентноспособности и экономической стабильности на мировой арене, что задает долгосрочные ориентиры совершенствования моделей управления национальными проектами и общественными инициативами. Цель статьи - проанализировать возможности социильно-проектной деятельности как технологии и ресурса эффективной социилизации молодежи.

Авторами выявлень основные характеристики современной социально-проектной деятельности, рассмотрень компетеничи, приобретаемые молодежью в ходе работы над проектами. Проанализировань успешные авторские сочиальные проекты из различных регионов Российской Федерации по различным номинациям Всероссийского конкурса молодежных авторских проектов и проектов сфере образования, направленных на соииально - экономическое развитие российских территорий «Моя страна - моя Россия». Выявлены и обощены технологии, повышаюшие качество социально-проектной деятельности молодежи и ресурсы ее успешной социиализации.

Abstract. A systematic approach to the sustainable development of Russia's socio-economic infrastructure is the basis of its competitiveness and economic stability in the world arena, which sets long-term guidelines for improving models of managing national projects and public initiatives. The purpose of the article is to analyze the possibilities of social-project activity as a technology and resource for effective socialization of youth.

The authors identified the main characteristics of modern social-project activities, considered the competencies acquired by young people in the course of work on projects. Analyzed are successful author's social projects from various regions of the Russian Federation in various nominations of the All-Russian competition of youth author's projects and projects in the field of education, aimed at the socio - economic development of Russian territories "My country - my Russia". The technologies that improve the quality of social-project activities of young people and the resources of their successful socialization have been identified and generalized.

Введение. Происходящий в настоящее время процесс смены доминирующих технологических укладов в мировой экономике также влияет на «российский вектор» долгосрочного социальноэкономического развития государства, обуславливает задачу непрерывного воспроизводства высококвалифицированных трудовых ресурсов [6], маштабного включения молодежи в управления проектами в сфре народного хозяйствования как «активного субъекта преобразования общества, драйвера развития и лидерства страны, так и объекта социализации, как ценнейший кадровый ресурс экономического роста и обеспечения благосостояния поколений» [14].

Сегодня задача расширения участия молодежи в проектной деятельности как сложного и системного процесса, связана с 
новыми условиями ее социализации в постиндустриальном обществе, что предполагает необходимость непрерывного роста у нее професиональных и социальных компетенций, а также с возможностью «применить свой опыт, знания и умения, находить оптимальное сочетание между целями, сроками, затратами, качеством и другими характеристиками проекта» [10].

Цель статьи - проанализировать возможности социально-проектной деятельности как технологии и ресурса эффективной социализации молодежи на основе обобщения педагогического опыта авторов.

Mатериаль $u$ методы. В статье использованы методы теоретического анализа, синтеза и педагогической интерпретации научных источников по теме исследования, а также метод педагогического наблюдения. Информационной базой выступили научные публикации по расссматриваемой теме исследования и авторские проекты из различных регионов Российской Федерации по различным номинациям Всероссийского конкурса молодежных авторских проектов и проектов сфере образования, направленных на социально экономическое развитие российских территорий «Моя страна - моя Россия».

Можно говорить о том, что проектное управление представляет собой прогрессивную технологию и одновременно с этим, ресурс акмеологии развития компетенций и социальнозначимых качеств личности молодого человека, что относит концепт «проектное управление как технология» к воспитательной сфере деятельности как педагогической, так и социальной категории. Учитывая, что понятие «технология» является междисциплинарным понятием, технологизация воспитательной работы в молодежной среде рассматривается нами в двух аспектах: 1) как целенаправленный набор форм, методов, способов, приёмов и организацонно-педагогических

средств,

повышающих результативность достижения воспитательных задач; 2) как процесс совершенствования качества воспитательной работы на основе декларируемых установок по проблеме воспитания и социализации молодого поколения со стороны личности, общества и государства в целом.

Поскольку педагогика является социальногуманитарной наукой и в поле ее зрения лежат процессы, имеющие для человека, общества и государства жизненно важное значение, осмысление теории и практики развития проектной деятельности как технология и ресурса более успешной социализации молодежи является еe прерогативой, т.к. направлена на решение проблем интеллектуального,социального и и и поликультурного развития личности. В связи с чем, социально-проектная деятельность при педагогическом сопровождении становится инструментом воспитания, самовоспитания и социализации [17].

По мнению исследователей, технологизация «воспитательной работы - это всегда совокупность целесообразных идей, воплощенных в конкретном наборе сфер, видов и форм деятельности, это движение к заданному эталону, идеальному образцу, это сочетание многих позитивных факторов, обстоятельств и создание условий для развития и воспитания духовных потребностей, положительных мотивов, желания и умения ответственно относиться к учению и труду, быть здоровым и культурным, уметь ценить, беречь и создавать красоту, участвовать в делах на благо группы, коллектива, общества» [5].

Данные выводы подтверждаются анализом достижений и результатов Всероссийского конкурса молодежных авторских проектов и проектов в сфере образования, направленных на социально-экономическое развитие российских территорий «Моя страна - моя Россия», в рамках которого за 18 лет деятельности проекта на разных уровнях открывались и внедрались инновационные социально-воспитательные технологии, которые показали свою эффективность и целосообразность более широкого внедрения в молодежной среде.

Во все времена «молодежь - это главная общественная ценность особого рода; это понятие не только демографическое, но и экономическое, социальное, политическое; это объективное общественное явление, представленное как болышая специфическая возрастная подгруппа, являющаяся носителем огромного интеллектуального потенциала, обладающая значительными способностями к творчеству, тогда как социальный же статус молодежи во всех конкретных обществах и во все времена в главном одинаков: молодежь одновременно объект и субъект социализации» [13].

Интересен научный факт, что рядом исследователей был выделен и актуализирован феномен позитивной социализации («позитивное развитие молодежи» (positive youth development (PYD), которая имеет отличительные признаки и характеризуется пятью терминами: «компетентность (competence) - социальная, когнитивная, академическая и профессиональная; 
уверенность (confidence) - уровень самоуважения и воспринимаемой самоэффективности в отношении себя как личности, а не в отношении каких-либо отдельных характеристик; связь (connection) - наличие положительной связи с людьми и социальными институтами; характер (character) - уважение к социальным и культурным правилам и нормам, владение стандартами поведения, чувство морали и чувство целостности; забота (caring) - чувство симпатии и эмпатии по отношению к другим людям» [3].

По мнению исследователей, предназначение и функции социально-воспитательной технологии характеризуют ее: 1) как совокупность психологопедагогических установок, определяющих набор и компоновку форм, методов, способов, приемов обучения и воспитательных средств [11]; 2) как процесс, системно управляемый планируемыми (ожидаемыми) результатами [7]. При этом, социально-проектная деятельность является социально-воспитательной технологией, синергетически объединяющей процесс воспитания, самовоспитания, социализации, в том числе и позитивной социализации.

Отметим, что «социализация - это процесс усвоения и активного воспроизведения человеком социального опыта, овладение навыками практической и теоретической деятельности, преобразования реально существующих отношений в качествах личности»[20].

Воспитание и социализация - сложные процессы, позитивный итог которых зависит от многих факторов, условий, среды и т.д. Воспитание - это «управление процессом развития личности через создание благоприятных для него условий» [19], а социализация - это «процесс освоения человеком социальных норм, включения в систему социальных отношений и складывания на этой основе его картины мира» [19]. Социализация имеет более широкое понятие, в которое тоже входит в том числе и воспитание. В воспитании участвуют два субъекта («человек и человек»), воспитание - это целенаправленный, контролируемый, но дискретный процесс.

Социализация представлена в контексте «человек и общество», субъект здесь только один, социализация стихийный, непрерывный процесс. Можно предположить, что социально-проектная деятельность является инструментом воспитания, самовоспитания, социализации, в том числе и позитивной социализации.

Байбородова Л.В., Серебренников Л.Н. считают, что социально-проектная деятельность решает важнейшие педагогические задачи:
— молодёжь применяет базовые знания и умения, которые усвоили на занятиях в учебных заведениях, для поиска и решения социальных, семейных, личных и других проблем;

- стимулирование самостоятельной познавательной деятельности молодежи (заинтересованы поиском способа решения поставленной ими проблемы, задачи, осваивают новую информацию и новые способы деятельности);

- молодежь рассматривает сложные объекты с точки зрения нескольких наук, используя большое количество аспектов, стирая границы между школьными, университетскими предметами;

- социально-проектная деятельность формирует различные социальные компетентности, многие личностные качества, профессиональные интересы [2].

Социально-проектная деятельность имеет свои требования, такие как наличие значимой проблемы, задачи, предполагаемых результатов; постановка цели, задач, определение проблемы; формулирование гипотезы; работа над проектом, которая предполагает путем самостоятельного добывания знаний - получение умений из различных областей; написание карты проекта (этапов); применение методов исследования; оформление проекта, результатов, анализирование данных; формулирование выводов, итогов, корректирование; внедрение, реализация проекта; рефлексия, работа над ошибками.

Отметим достоинства социально-проектной деятельности: создание комфортного образовательного и воспитательного пространства, позитивная социализация молодежи, приобретение, развитие, совершенствование навыков (самостоятельность, умение добывать и применять знания, умение работать в команде, навыки критического мышления, исследовательские и организаторские умения).

Под социально-проектной деятельностью, Пастухова Л.С. понимает такую деятельность, результатами которой является: социально полезный продукт, решение социальной проблемы, получение участниками проекта социокультурных компетентностей, переход от группы молодых людей в команду, команды в сообщество и другие формы социально-деловых коммуникаций [15].

Социально-проектная деятельность из-за возможности без принуждённого участия имеет мотивационную составляющую, молодежь имеет право выбора, свободы, они сами контролируют 
степень разработанности, внедрения и других этапов проекта. Работая над социальноориентированным проектом, молодежь занимается социальным проектированием, а вся деятельность (от идеи до реализации и потом рефлексии) называется социально-проектной деятельностью, т.е. с помощью социальнопроектной деятельности можно создавать проекты, которые улучшают жизнь общества и это средство называется социальным проектированием.

По мнению Пастуховой Л.С. и Ивановой С.В. в процессе разработки и реализации проекта молодые люди приобретают такие компетенции как: ценностно-смысловую, общекультурную, учебно-познавательную, информационную, коммуникативную, социально-трудовую, личностную [9].

Под социальным проектированием понимается самостоятельная деятельность обучающихся, направленная на практическое решение общественно-значимой проблемы, способствующая взаимодействию молодежного сообщества с властными структурами и общественностью [8;12]. Алюкова О.Ю. трактует понятие социального проектирования как «научно-теоретическую и одновременно предметно-практическую деятельность по созданию проектов развития социальных систем, институтов, социальных объектов, их свойств и отношений на основе социального предвидения, прогнозирования и планирования социальных качеств и свойств, являющихся значимой социальной потребностью» [1].

Как отмечают некоторые исследователи (Тощенко Ж.Т., Сафина А.А., Тазетдинова И.Т.) «социальное проектирование - это специфическая деятельность, связанная с научно обоснованным определением вариантов развития новых социальных процессов и явлений и с целенаправленным коренным изменением конкретных социальных институтов» [18]. Главной чертой социального проектирования является способность определять потребности людей, региона, малой Родины, исходя из этого решать реальные проблемы общества. При этом социальное проектирование становится инструментом (примером) позитивной социализации (происходит усвоение компетенций, формируется характер, возникает связь с обществом, возникает чувство уверенности в себе и в своих силах, а также социальный проект - это проявление заботы об обществе), стихийной социализации (процесс непреднамеренного влияния общества на молодого человека).

Таким образом, обобщая результаты теоретического анализа, авторы понимают социальное проектирование как средство или инструмент, благодаря которому формируется умение ставить цели, находить пути их достижения, а также эффективно использовать ресурсы.

Результаты. Интересным примером эффективной реализации социально-проектной деятельности как инструмента социализации молодежи выступает Всероссийский конкурс «Моя страна - моя Россия» (далее - Конкурс), который направлен на социально-экономическое развитие российских территорий. Конкурс реализуется с 2003 года и нацелен на привлечение молодежи в возрасте от 14 до 35 лет.

Количество участников конкурса «Моя страна - моя Россия»

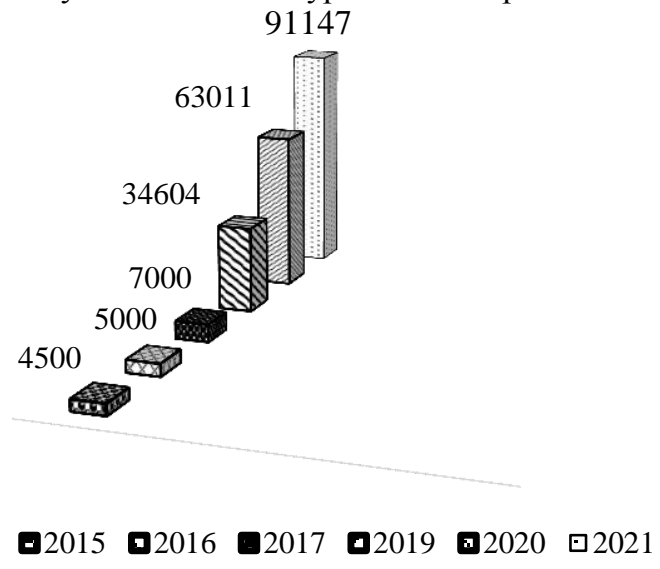

Рисунок 1. - Количество участников Всероссийского конкурса «Моя страна - моя Россия» в период с 2015 nо 2021 г2. 
Рисунок 1 показывает, что количество участников ежегодно растет, что с одной стороны говорит о росте популярности в молодежной среде, с другой, - о заинтересованности педагогов и преподавателей работать с молодежью с эффективным применением «проектного метода».

Практика проведения Всероссийского конкурса молодежных авторских проектов и проектов в сфере образования «Моя страна - моя Россия» выявила, что «проектный метод» стал эффективной технологией для организации междисциплинарной работы молодежью: он создает возможности для развития новых подходов к воспитанию и социализации молодого поколения. Добавим, что сегодня проектный метод активно применяют талантливые педагоги нашей страны, показывая замечательные результаты и работая над своими проектами, юные участники конкурса опираются и на мнение старших, и на нашу историю, и на свои личные наблюдения и опыт, вот так проявляется важная составляющая социально-проектной деятельности - преемственность, диалог между поколениями [4;16].

На рисунке 2, представлено распределение конкурсантов по номинациям результатов 2021 года. Инфографика наглядно демонстрирует интерес молодежи к проблемам в обществе. К примеру, наибольшее количество проектов в номинации «Моя педагогическая инициатива» 17,29\% (это может быть связано с тем, что возврат участников в этой номинации не ограничен), «Моя гордость. Моя малая Родина» $14,23 \%$, «Экология моей страны» $12,45 \%$ и специальная номинация «Сказки о космосе» 11,7\% (возврат участников до 13 лет).

Рассматривая социальные проекты Конкурса «Моя страна - моя Россия» можно понять проблемные вопросы, волнующие молодежь.

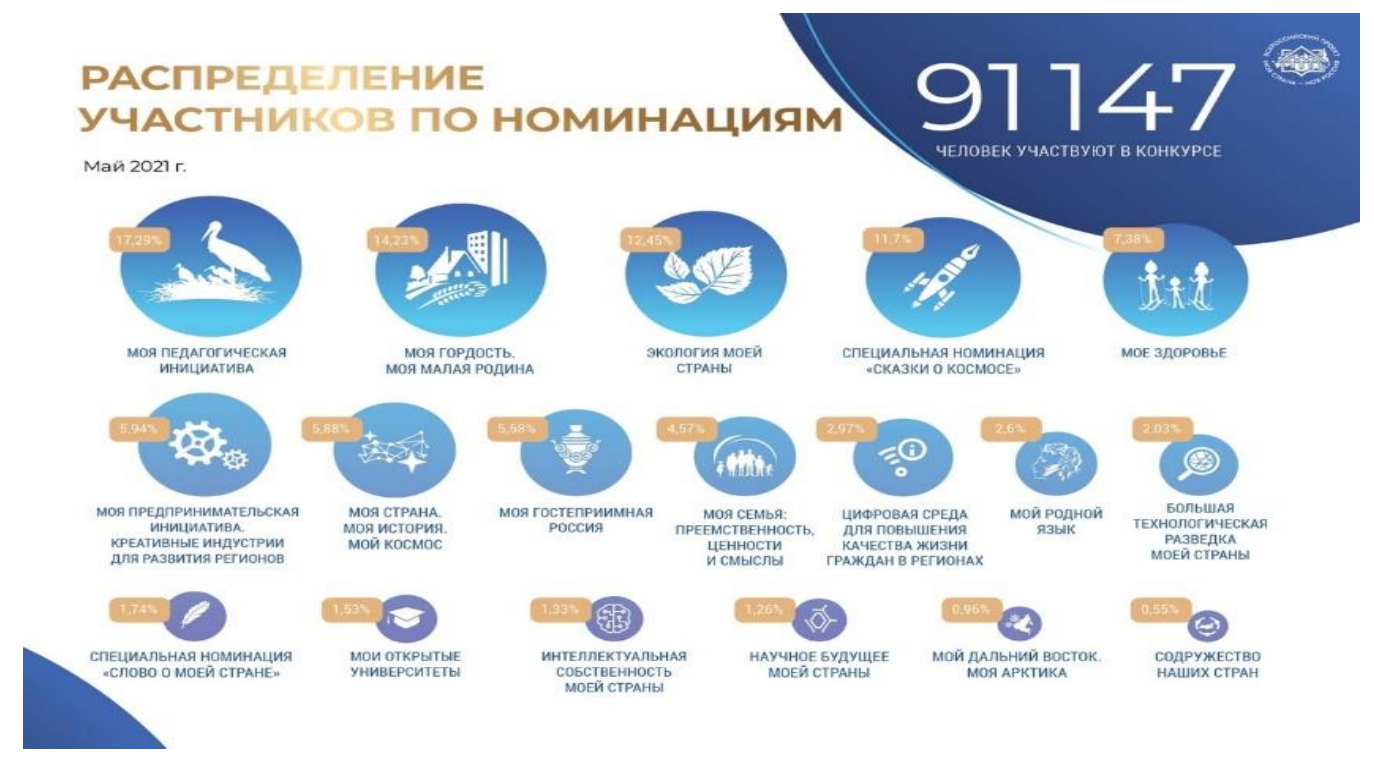

Рисунок 2. - Распределение конкурсантов по номинациям результатов проекта в 2021 году

Приведем несколько примеров. Вероника Мелихова, школьница из Приморского края, подготовила проект «Помним. Гордимся. Храним», который направлен на восстановление истории своего села в годы Великой Отечественной войны.

Идея проекта зародилась, когда Вероника решила узнать, какой вклад в Победу внесли ее прадеды, но оказалось, что информации совсем немного. При поддержке сельской библиотеки было решено провести сбор сведений о герояходносельчанах. В процессе работы возник вопрос и об истории возникновения села.

Проект включал в себя составление Книги памяти. Получив поддержку района, партнеров, проект реализуется до сих пор. Открыт обелиск участникам войны к 74-ой годовщине Победы, проведена (впервые в селе) акция «Бессмертный полк». Сама Вероника говорит, что очень любит свою малую Родину, считает, что нужно знать историю своего села, города, района, страны.

Мария Зинкина, студентка колледжа, подготовила проект, в котором представила экологичную технологию производства бумаги. Участники команды изучили процесс производства бумаги из древесины, и в ходе экспериментальной работы в лаборатории колледжа молодые люди разработали собственную технологию изготовления бумаги из сухой травы и листьев. Производство такой 
бумаги является экономически выгодным, безотходным. Данный проект направлен на сокращение вырубки лесов.

Еще одним успешным проектом является «Чемодан сказок» Алены Вакульчик, школьницы Калининградской области. Команда Алены ездит по Калининградской области с декорированным чемоданом и рассказывает сказки пациентам детской областной больницы, а также проводит Добрые уроки в школах, рассказывая о добровольчестве. Проект показал замечательный результат: появилось много добровольцев, волонтеров, которые продолжают проект.

Юлия Анисимова из города Кемерово разработала систему связи и оповещения для связи диспетчеров с шахтёрами угольных предприятий которая предоставляет данные о местоположении в случае обвалов и других чрезвычайных происшествий.

Студент Дмитрий Заремба разработал биотехнологии очистки промышленных сточных вод, используя микроорганизмы активного ила.

Выше приведенные примеры дают основания предположить, что молодежь занимаясь социально-проектной деятельностью повышает общекультурный уровень, формирует социальноличностные компетенции и другие социальные навыки и умения, развивает мобильность, организаторские и коммуникативные спсобности и социально-значимые личные качества. Опыт работы над Конкурсом показывает, что идет рост социальной активности молодежи, которая заинтересована в получении социально-значимых навыков и стремится к творчекой самореализации, а также помогать обществу, менять мир, получать новые знакомства и связи. В связи с чем, педагогическому сообществу следует более внимательно относиться к зарождавшимся социальным инициативам молодежи и поддерживать ее на всех уровнях и этапах.

Заключение. Социально-проектная деятельность, широко представленная в современной практике работы с молодежью, может выступать социально-педагогической технологией, направленной на более успешное освоение общекультурных, образовательных и профессиональных компетенций, а также стать ресурсом непрерывного развития личности, ее уверенности в успехе своей трудовой деятельности, активизации социально-деловых коммуникаций и укрепления гуманистического мировоззрения, что является фактором позитивной социализации.

Bce вышесказанное говорит о том, что социально-проектная деятельность молодежи по своей сути и содержанию является социальнопедагогическим технологическим процессом инновационной направленности, выделяющемся среди других современных подходов к образованию и воспитанию, и требующим более глубокого научного анализа и разработки прикладных моделей более широкого внедрения в молодежной среде.

\section{Лumepamypa:}

1. Алюкова О.Ю. Социальное проектирование как способ формирования созидательной активности современной молодежи: коллективная монография / О.Ю. Алюкова, А.Ю. Нагорнова // Социальное поведение личности: оценки и стратегии. - Ульяновск: ИП Кеньшенская Виктория Валерьевна (издательство «Зебра»), 2016. - С. 224-236.

2. Байбородова Л.В., Серебренников Л.Н. Проектная деятельность как средство профессионального самоопределения школьников [Электронный ресурс] / Л.В. Байбородова, Л.Н. Серебренников // Ярославский педагогический вестник. - 2014. - № 2. - Режим доступа: https://cyberleninka.ru/article/n/proektnaya-deyatelnostkak-sredstvo-professionalnogo-samoopredeleniyashkolnikov

3. Волкова Е.Н., Вереитинова Т.В. К определению понятия позитивной социализации молодежи [Электронный ресурс] / Е.Н. Волкова, Т.В. Вереитинова, И.В. Волкова, О.С. Михалюк // Вестник Мининского университета. - 2016. - № 2(15). - Режим доступа: https://cyberleninka.ru/article/n/k-opredeleniyuponyatiya-pozitivnoy-sotsializatsii-molodezhi
4. Всероссийский конкурс «Моя страна - моя Россия» [Электронный ресурс]. - Режим доступа: www.moyastrana.ru

5. Вульфов Б.З., Иванов В.Д. Основы педагогики в лекциях, ситуациях, первоисточниках: учебное пособие / Б.З. Вульфов, В.Д. Иванов. - М.: Изд-во УРАО, 1997. - $288 \mathrm{c}$.

6. Глазьев С.Ю. Стратегия опережающего развития российской экономики в условиях глобального кризиса / С.Ю. Глазьев. - М.: Экономика, 2010.

7. Загорулько Р.В. Педагогические системы и технологии: практический аспект: курс лекций / Р.В. Загорулько, Н.А. Ракова, Л.И. Шевцова. - Витебск: Издательство УО «ВГУ им. П.М. Машерова», 2009. $194 \mathrm{c}$.

8. Иванова С.В. О политическом проектировании и проектной деятельности в сфере политики [Электронный ресурс] / С.В. Иванова // Пространство и Время. - 2011. - № 1. - Режим доступа: https://cyberleninka.ru/article/n/o-politicheskomproektirovanii-i-proektnoy-deyatelnosti-v-sfere-politiki 
9. Иванова С.В., Пастухова Л.С. Возможности использования проектного метода в образовании и работе с молодежью на современном этапе [Электронный ресурс] / С.В. Иванова, Л.С. Пастухова // Образование и наука. - 2018. - № 6. - Режим доступа: https://cyberleninka.ru/article/n/vozmozhnostiispolzovaniya-proektnogo-metoda-v-obrazovanii-i-rabotes-molodezhyu-na-sovremennom-etape

10. Катышевская Т.А.Сущность проектной деятельности: сборник научных статей / T.А. Катышевская // «СКИФ. Вопросы студенческой науки». - Санкт-Петербург. - 2020. - Выпуск 2(42).

11. Лихачев Б.Т. Педагогика: курс лекций / Б.Т. Лихачев. - 3-е изд., испр. и доп. - М., 1998. - 464 с.

12. Макарова Р.Т. Технология социального проектирования [Электронный ресурс] / Р.Т. Макарова // Инновационные проекты и программы в образовании. - 2011. - № 1. - Режим доступа: https://cyberleninka.ru/article/n/tehnologiya-sotsialnogoproektirovaniya

13. Норцев Д.С. Особенности реализации региональных молодежных программ в России и США / Д.С. Норцев // Вестник ПАГС. - 2015. - № 5. - С. 121126.

14. Основы государственной молодежной политики Российской Федерации на период до 2025 года / Утверждено правительством РФ, распоряжение от 29 ноября 2014 г. № 2403-р.

15. Пастухова Л.С. Социально-проектная деятельность в воспитании и социализации молодого человека: анализ практического опыта [Электронный peсурс] / Л.С. Пастухова // Педагогический журнал Башкортостана. - 2018. - № 5(78). - Режим доступа: https://cyberleninka.ru/article/n/sotsialno-proektnaya- deyatelnost-v-vospitanii-i-sotsializatsii-molodogo-

cheloveka-analiz-prakticheskogo-opyta

16. Пастухова Л.С. Социально-проектная деятельность как открытое воспитательное пространство развития гражданских качеств молодежи / Л.С. Пастухова // Вестник Марийского государственного университета. - 2019. - Т. 13. - № 2. С. 289-294.

17. Пастухова Л.С. Педагогическая экспертиза социально-проектной деятельности молодежи / Л.С. Пастухова // Известия Российской академии образования. - 2018. - № 3(47). - С. 67-82.

18. Сафина А.А., Тазетдинова И.Т. Социальное инновационное проектирование и опыт подготовки к нему будущих специалистов социальной работы [Электронный ресурс] / А.А. Сафина, И.Т. Тазетдинова // Вестник Казанского технологического университета. - 2010. - № 3. - Режим доступа: https://cyberleninka.ru/article/n/sotsialnoe-innovatsionnoeproektirovanie-i-opyt-podgotovki-k-nemu-buduschihspetsialistov-sotsialnoy-raboty

19. Степанов П.В. Современная теория воспитания: словарь-справочник / П.В. Степанов; под ред. Н.Л. Селивановой. - М.: Изд-во: АНО Издательский Дом «Педагогический поиск», 2016. - 48 c.

20. Терминологический словарь-справочник по психолого-педагогическим дисциплинам [Электронный ресурс] / Т.М. Баринова, И.О. Гарипова, В.В. Каранова, Н.П. Леонова и др. - Режим доступа: https://didacts.ru/slovari/terminologicheskii-slovarspravochnik-po-psihologo-pedagogicheskimdisciplinam.html

\section{Reference:}

1. Alyukova O.Yu. Social design as a way of forming the creative activity of modern youth: collective monograph / O.Yu. Alyukova, A.Yu. Nagornova // Social behavior of the individual: assessments and strategies. - Ulyanovsk: IE Kenshenskaya Victoria Valerievna (publishing house "Zebra"), 2016. - Pp. 224-236.

2. Bayborodova L.V., Serebrennikov L.N. Project activity as a means of professional self-determination of schoolchildren [Electronic resource] / L.V. Bayborodova, L.N. Serebrennikov // Yaroslavl Pedagogical Bulletin. 2014. - № 2. - Access mode: https://cyberleninka.ru/article/n/proektnaya-deyatelnostkak-sredstvo-professionalnogo-samoopredeleniyashkolnikov

3. Volkova E.N., Vereitinova T.V. To the definition of the concept of positive socialization of youth [Electronic resource] / E.N. Volkova, T.V. Vereitinova, I.V. Volkova, O.S. Mikhalyuk // Bulletin of Minin University. - 2016. - № 2(15). - Access mode: https://cyberleninka.ru/article/n/kopredeleniyu-ponyatiya-pozitivnoy-sotsializatsii-molodezhi

4. All-Russian competition "My country - my Russia" [Electronic resource]. - Access mode: www.moyastrana.ru

5. Vulfov B.Z., Ivanov V.D. Fundamentals of pedagogy in lectures, situations, primary sources: textbook /
B.Z. Vulfov, V.D. Ivanov. - M.: Publishing house of URAO, 1997. - 288 p.

6. Glazyev S.Yu. Strategy of the outstripping development of the Russian economy in the context of the global crisis / S.Yu. Glazyev. - M.: Economics, 2010.

7. Zagorulko R.V. Pedagogical systems and technologies: practical aspect: a course of lectures / R.V. Zagorulko, N.A. Rakova, L.I. Shevtsov. - Vitebsk: Publishing house of the UO "VSU im. P.M. Masherova", 2009. - 194 p.

8. Ivanova S.V. About political projection and project activity in the sphere of politics [Electronic resource] / S.V. Ivanova // Space and Time. - 2011. - № 1. - Access mode: https://cyberleninka.ru/article/n/o-politicheskomproektirovanii-i-proektnoy-deyatelnosti-v-sfere-politiki

9. Ivanova S.V., Pastukhova L.S. Possibilities of using the design method in education and work with youth at the present stage [Electronic resource] / S.V. Ivanova, L.S. Pastukhova // Education and Science. - 2018. - № 6. Access mode: https://cyberleninka.ru/article/n/ vozmozhnosti-ispolzovaniya-proektnogo-metoda-vobrazovanii-i-rabote-s-molodezhyu-na-sovremennom-etape

10. Katyshevskaya T.A. The essence of project activity: a collection of scientific articles / T.A. 
Katyshevskaya // SKIF. Students' Science Issues. - St. Petersburg. - 2020. - Issue 2 (42).

11. Likhachev B.T. Pedagogy: a course of lectures / B.T. Likhachev. - 3rd ed., Rev. and add. - M., 1998. - 464 p.

12. Makarova R.T. Technology of social design [Electronic resource] / R.T. Makarova // Innovation projects and programs in education. - 2011. - № 1. - Access mode: https://cyberleninka.ru/article/n/tehnologiya-sotsialnogoproektirovaniya

13. Nortsev D.S. Features of the implementation of regional youth programs in Russia and the USA / D.S. Nortsev // Bulletin of PAGS. - 2015. - № 5. - S. 121-126.

14. Fundamentals of the state youth policy of the Russian Federation for the period up to 2025 / Approved by the government of the Russian Federation, order of November 29, 2014 No. 2403-r.

15. Pastukhova L.S. Socio-project activity in education and socialization of a young person: analysis of practical experience [Electronic resource] / L.S. Pastukhova // Pedagogical journal of Bashkortostan. - 2018. - № 5(78). Access mode: https://cyberleninka.ru/article/n/sotsialnoproektnaya-deyatelnost-v-vospitanii-i-sotsializatsiimolodogo-cheloveka-analiz-prakticheskogo-opyta

16. Pastukhova L.S. Socio-project activity as an open educational space for the development of civic qualities of youth / L.S. Pastukhova // Bulletin of the Mari State University. - 2019. - T. 13. - № 2. - S. 289-294.

17. Pastukhova L.S. Pedagogical examination of the social-project activity of youth / L.S. Pastukhova // Bulletin of the Russian Academy of Education. - 2018. - № 3 (47). S. 67-82.

18. Safina A.A., Tazetdinova I.T. Social innovative design and the experience of training future specialists in social work [Electronic resource] / A.A. Safina, I.T. Tazetdinova // Bulletin of Kazan Technological University. - 2010. - № 3. - Access mode: https://cyberleninka.ru/article/n/sotsialnoe-innovatsionnoeproektirovanie-i-opyt-podgotovki-k-nemu-buduschihspetsialistov-sotsialnoy-raboty

19. Stepanov P.V. Modern theory of education: dictionary-reference book / P.V. Stepanov; ed. N.L. Selivanova. - M.: Publishing house: ANO Publishing House "Pedagogical Search", 2016. - 48 p.

20. Terminological dictionary-reference book on psychological and pedagogical disciplines [Electronic resource] / T.M. Barinov, I.O. Garipova, V.V. Karanova, N.P. Leonova and others - Access mode: https://didacts.ru/slovari/terminologicheskii-slovarspravochnik-po-psihologo-pedagogicheskimdisciplinam.html

13.00.01 - Общая педагогика, история педагогики и образования

\section{Сведения об авторах:}

Турлаков Дмитрий Геннадиевич (г. Москва, Россия), аспирант, руководитель исполнительной дирекции Всероссийского конкурса «Моя страна - моя Россия», Московский политехнический университет, e-mail: dmi-turlakov@yandex.ru

Турлакова Ольга Евгеньевна (г. Москва, Россия), аспирант, специалист детского технопарка НИЦ «Курчатовский институт», Институт стратегии развития образования PAO, e-mail: olenka1592@mail.ru

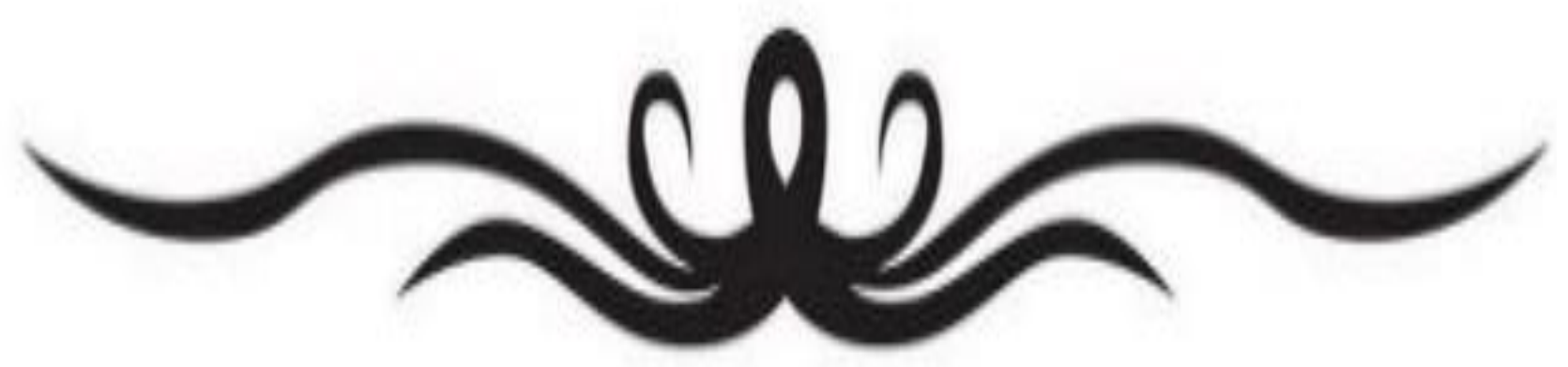

